\title{
New data on the Late Cretaceous lizard Dicothodon bajaensis (Squamata, Borioteiioidea) from Baja California, Mexico reveals an unusual tooth replacement pattern in squamates
}

\author{
MARÍA LUISA CHAVARRÍA-ARELLANO' ${ }^{1}$, TIAGO R. SIMÕES ${ }^{2}$ \\ and MARISOL MONTELLANO-BALLESTEROS ${ }^{3}$ \\ ${ }^{1}$ Universidad Nacional Autónoma de México, Posgrado en Ciencias Biológicas, Instituto de Geología, \\ Investigación Científica, Copilco Cd. Universidad, Coyoacán, 04510, Ciudad de México, CDMX, México \\ ${ }^{2}$ University of Alberta, Department of Biological Sciences, 11645, Saskatchewan Drive, Edmonton, Alberta, T6G 2E9, Canada \\ ${ }^{3}$ Universidad Nacional Autónoma de México, Instituto de Geología, Investigación Científica, \\ Copilco Cd. Universidad, Coyoacán, 04510, Ciudad de México, CDMX, México
}

Manuscript received on July 21, 2017; accepted for publication on December 18, 2017

\begin{abstract}
Borioteiioids comprise an extinct family of squamates that inhabited the Northern Hemisphere during the Cretaceous and were characterized by varying patterns of tooth replacement and dental morphology. Understanding the evolution of these tooth replacement patterns has, however, been largely hampered by an extremely fragmentary fossil record. Here we present new information on Dicothodon bajaensis from the Campanian of Baja California (Mexico), so far known only from isolated teeth and jaw fragments. Among abundant new materials there are ten maxillae and five dentaries belonging to distinct ontogenetic stages. Whereas juveniles display active tooth replacement, older specimens show no evidence of replacement. Dicothodon bajaensis is therefore inferred to have had arrested tooth replacement later in ontogeny. This provides the first evidence of cessation of tooth replacement during late ontogeny in lizards (living or extinct). This replacement type is also an evolutionary intermediate between the typical lizard replacement pattern, observed in some borioteiioids (e.g., Bicuspidon) and the complete absence of tooth replacement since early ontogeny as observed in other borioteiioids (e.g., Polyglyphanodon).
\end{abstract}

Key words: Campanian, dental morphology, Mexico, North America, Squamata, tooth replacement.

\section{INTRODUCTION}

Tooth replacement in most reptiles occurs throughout their whole life (Edmund 1960, 1969, Osborn 1974, Berkovitz 2000). Older functional teeth are periodically shed and substituted by replacement teeth that are continuously formed in a dental lamina which, within squamates (lizards, snakes

Correspondence to: María Luisa Chavarría-Arellano

E-mail: mariachavarria@outlook.com and amphisbaenians), is placed lingually to the tooth row. Each replacement tooth eventually migrates labially and enters the pulp cavity of the functional tooth through a resorption pit located at the base of the latter, and continues to develop within it until the functional tooth is shed (Edmund 1960, Cooper 1966). This process is observed in a vast number of squamate lineages (e.g., most iguanians, geckoes, cordylids, lacertids, teiioids, and scincids), but some important deviations from this pattern may occur. 
An unusual replacement pattern occurs within acrodontan lizards (agamids and chameleons), in which tooth replacement occurs during embryonic developmental stages, but ceases in post-embryonic ontogeny in the posterior tooth series (although new teeth continue to be added posteriorly on the tooth row until later in ontogeny). The anteriormost maxillary and dentary teeth in acrodontans are still replaced during post-embryonic ontogeny, but even among those, tooth replacement ceases during early ontogeny (Cooper et al. 1970, Cooper and Poole 1973). In some extreme cases, there is no tooth replacement at all during post-embryonic life, such as in the agamids Calotes (Edmund 1960) and Uromastyx (Cooper and Poole 1973). Recently, it has been identified that in agamids and chameleons the cessation of replacement occurs due to a dramatic reduction in the size of the successional lamina (which becomes vestigial), thus, not producing any tooth germs for replacement tooth generations (Richman and Handrigan 2011, Buchtová et al. 2013).

Among fossil squamates, important clues regarding patterns of tooth development and replacement have been discovered in the last decades. Some of these findings have elucidated important questions and given new insights into the evolutionary history of mosasaurs, snakes and acrodontans (Nydam et al. 2000, Caldwell et al. 2003, Budney et al. 2006, Caldwell 2007, Luan et al. 2009, Simões et al. 2015). Concerning the evolution of acrodonty and arrested tooth development, two particular fossil squamate lineages are of great relevance: priscagamids and borioteiioids. Priscagamids lived during the Late Cretaceous in Mongolia, China and Central Asia (Nessov 1988, Borsuk-Bialynicka 1996) and exhibited a similar pattern of arrested tooth replacement to that seen in acrodontans. Priscagamids are considered to be the sister clade to Acrodonta (Gauthier et al. 2012, Simões et al. 2017, Pyron 2017) and thus, their pattern of tooth replacement has been considered homoplastic to the acrodontan condition (BorsukBialynicka 1996, Simões et al. 2015).

The ontogenetic and evolutionary patterns concerning tooth development and replacement in borioteiioids - a clade from the Late Cretaceous of North America, East Asia, and Europe (Gao and Norell 2000, Folie and Codrea 2005, Nydam et al. 2007) - is, on the other hand, more enigmatic. Arrested tooth replacement has been identified in North American borioteiioids, such as Polyglyphanodon sternbergi (Nydam and Cifelli 2005) and also suggested for Peneteius aquilonius (Nydam et al. 2000). However, most Cretaceous North American lizards, apart from Po. sternbergi, have a very limited record and specimen sample size (mostly being fragmentary jaws and isolated teeth), thus, preventing a thorough understanding of the patterns of tooth replacement during ontogeny (Nydam et al. 2000, 2007, 2013). Additionally, even for Pe. aquilonius and Po. sternbergi there are still important unanswered questions regarding their tooth replacement patterns. For instance, it is known that juvenile and adults of Po. sternbergi lacked tooth replacement (Nydam and Cifelli 2005), but it is unknown at which ontogenetic stage that replacement ceased.

Here we report on and describe numerous new materials of the fossil lizard Dicothodon bajaensis Nydam et al. 2007 from the Campanian of Baja California, Mexico (Chavarría-Arellano 2014, García-Alcantara 2016, Montellano-Ballesteros et al. 2005, 2008, Romo de Vivar 2011). These new specimens offer a unique opportunity to re-examine tooth replacement patterns in D. bajaensis, and therefore shed some light on the patterns of tooth development and replacement among borioteiioids from the Cretaceous of North America. Importantly, an unusual pattern of replacement is observed that might be unique to borioteiioids, as it is thus far unknown from any other clade of squamates, either living or extinct. 


\section{MATERIALS AND METHODS}

Observations and measurements on dental morphology, tooth replacement patterns, and overall morphology of tooth bearing bones in $D$. bajaensis were performed using a wide range of techniques. These include: personal observations of the referred specimens using dissecting stereomicroscopes (Olympus SZ61), radiographic images (X Mind Satelec), three-dimensional micro computer-tomography scans (CT scans) were taken at Laboratorio Nacional de Manufactura Aditiva, Digitalización 3D y Tomografía Computarizada, UNAM (Nikon Metrology XT H 225 at 215 kV and $32 \mathrm{uA}$ with an exposure time of $500 \mathrm{~ms}$ ). The software myVGL 3.0 was used to create the two-dimensional images, and high resolution photographs (Nikon D3300 digital camera). Drawings were created using Adobe Photoshop CC 14.0. Additionally, we obtained pictures of Adamisaurus magnidentatus (MgR- III/5, MgRIII/3, MgR-III/1 and MgR-II/50) donated by Dr. Adam Halanski.

The fossil materials of Dicothodon bajaensis were collected during multiple field trip seasons to the outcrops of the 'El Gallo' Formation, in the area of El Rosario, Baja California, Mexico. The specimens were collected on the surface, by screenwashing in four different microsites (Figure 1): Evelia, 0km, Scorpio, and CADAEL. The materials were subsequently transported to and prepared at the Laboratorio de Paleontología, Instituto de Geología, Universidad Nacional Autónoma de México(UNAM), in Mexico City, using mechanical preparation techniques (entomological needles and air scribes).

Measurements: The length of the dentaries was measured from the first tooth position to the last tooth position. Dentary height was taken from the base of exposed tooth crown of last tooth position to the ventral edge of the jaw. The length of the maxillae was performed from the last posterior molariform tooth to the first molariform tooth, as most maxillae are too incomplete for a whole maxilla length measure. The relative sizes of replacement teeth were taken from the CT scan data, following the guidelines of Delgado et al. (2003). Functional and replacement tooth crown heights were taken from the tooth apex to a line circumscribing the tooth bases as seen in lingual

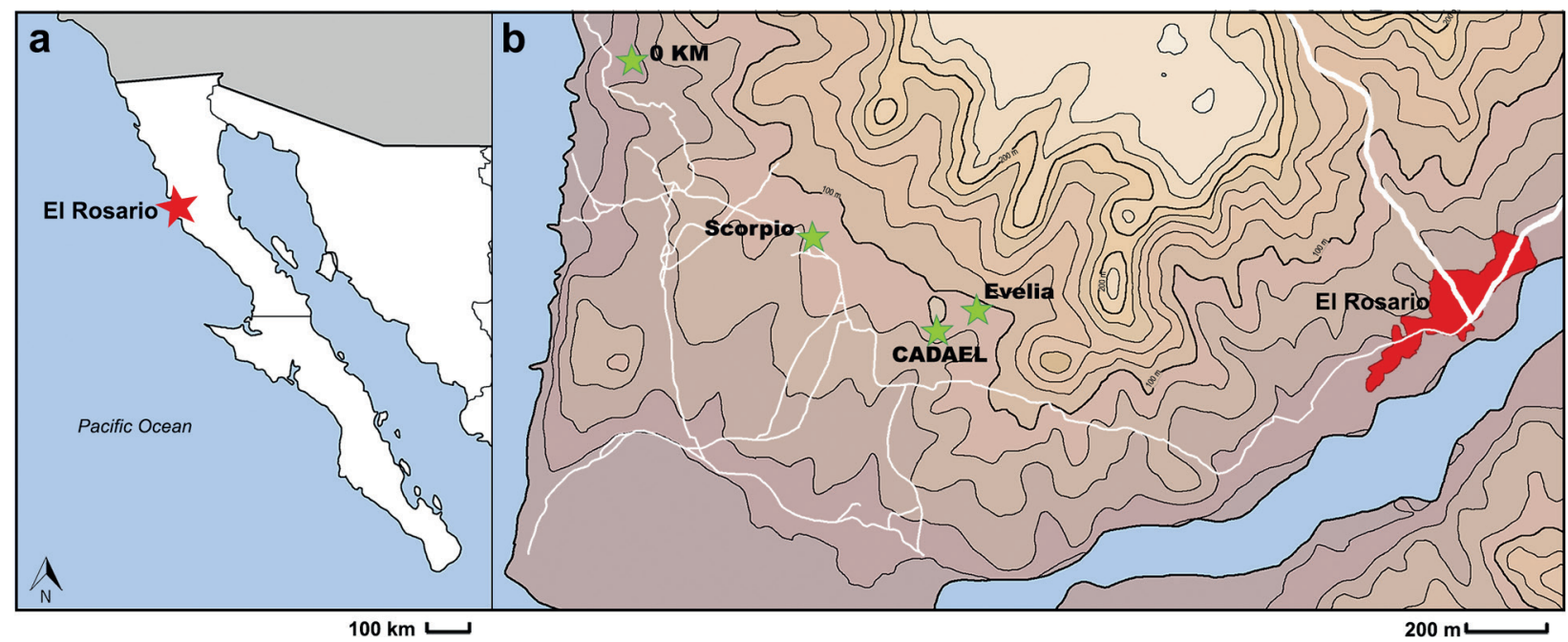

Figure 1 - a, location of the town of El Rosario, Baja California, Mexico; b, enlarged map of El Rosario area showing the four microsites where the referred specimens have been collected: Evelia (IGM 4970, IGM4971, IGM4972); 0KM (IGM4973, IGM4974, IGM4975, IGM4976, IGM4977, IGM4978, IGM4979, IGM4983); Cadael (IGM4980, IGM4981, IGM4984); Scorpio (IGM4982). 
view. Relative tooth sizes also follows Delgado et al. (2003): replacement tooth height divided by the functional tooth crown height.

Ontogenetic markers: Ontogenetic stages were assessed based on individual measurements and discrete ontogenetic markers. Squamates add teeth to the back of their tooth row during ontogeny, following growth of the jaw bone (Edmund 1969, Estes and Williams 1984). This pattern is especially important for squamates that lack tooth replacement, as this is the only means by which new teeth are added to the tooth row (Edmund 1960, 1969, Cooper et al. 1970, Cooper and Poole 1973). Therefore, once the jaws stop growing no more teeth are added posteriorly to the tooth row in squamates, thus characterizing a useful ontogenetic marker for skeletal maturity that can be applied to assess skeletal maturity in fossil lizards (Apesteguía et al. 2016). Following this rationale, two discrete ontogenetic markers have been used besides measurement data: i) presence and absence of teeth still being added posteriorly on the tooth row (see also Supplementary Material); and ii) ankylosis of the posteriormost tooth to the tooth-bearing bone.

Nomenclature for tooth wear and resorption pits: The dentition was classified as having no wear when no signs of abrasion were apparent; with moderate wear when abrasion was present, but the lingual and labial cusps were still complete (Figure 2f); and finally, as having a high degree of wear when both the tooth enamel and cusps were completely abraded. For the categorization of the resorption pits, we used the following nomenclature: open, when resorption pits were circular and well-developed; incipient, when the resorption pit was still very small ("slit-like") and not fully open; and absent, for specimens lacking resorption pits.

The materials are housed at the Colección Nacional de Paleontología "María del Carmen Perrilliat”, Instituto de Geología, UNAM (IGM). The studied specimens of Dicothodon bajaensis include: one premaxilla (IGM4972), nine upper jaws (IGM4970b, IGM4971, IGM4973, IGM4974, IGM4976, IGM4977, IGM4979, IGM4980 and IGM4983), four lower jaws (IGM4970a, IGM4975, IGM4978 and IGM4981), left jaws in occlusion (IGM4982) and isolated teeth (IGM4982).

\section{DESCRIPTION}

Here we provide a detailed description of the dentition of Dicothodon bajaensis, which has implications for patterns of tooth replacement and diet inference for this taxon. Additional description of the skull and postcranial materials will be provided elsewhere (MLC, work in progess).

\section{DENTAL MORPHOLOGY}

Premaxillary dentition: IGM4972 is the only specimen with the premaxilla. The premaxillae are fused to each other and have a part of the nasal process preserved. The premaxillary teeth are attached to the lingual side of the premaxilla, they are partially ankylosed to the premaxillary bone and no resorption pits are observed. The anteriormost premaxillary teeth are conical, posteriorly curved and bear circular bases (Figure 2b). Additionally, the premaxillary teeth are closely spaced and of similar height to each other.

Maxillary dentition: Maxillary teeth are attached apicolingually to the labial wall of the maxilla throughout the entire tooth row. All teeth display a high degree of ankylosis to the maxillary bone when they are fully functional. The only specimen with the maxillary dentigerous portion entirely preserved has 15 tooth positions (IGM4980). The dentition is heterodont, including seven small conical anterior teeth that are slightly curved lingually and have circular tooth bases. This anterior series is succeeded by eight transversally expanded and bicuspid molariform posterior teeth that become progressively higher and stouter distally (Figure 3q, t). The posterior teeth have equally developed labial and lingual cusps 

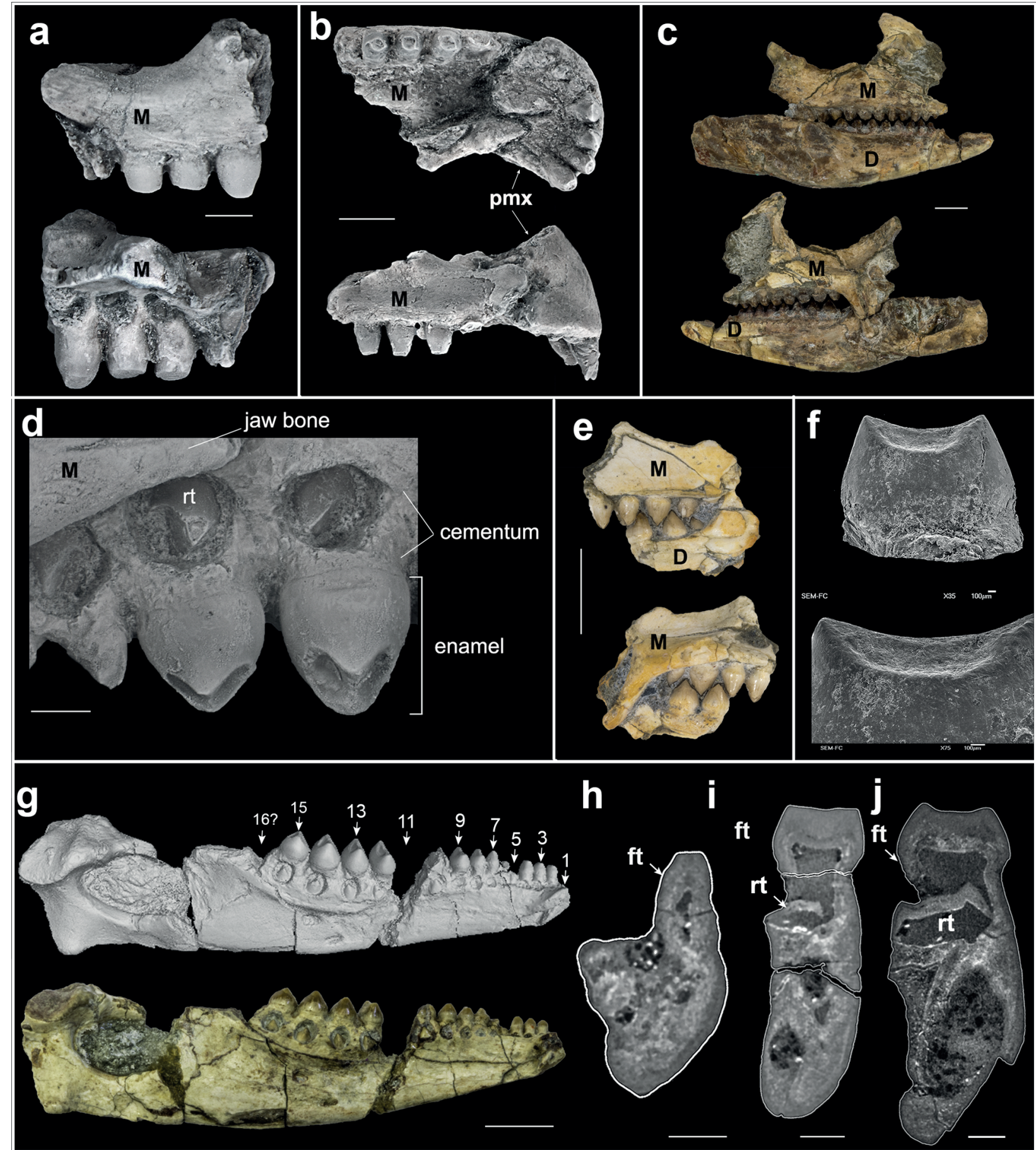

Figure 2 - a, labial and lingual views of the most anterior part of the left maxilla (IGM4979); b, premaxila and the most anterior part of the right upper jaw in occlusal and labial views (IGM4972); c, labial and lingual views of the upper and lower jaw in occlusion (IGM4970); d, close up of the last tooth position (IGM4977); e, labial and lingual views of the most posterior fragments of upper and lower jaws in occlusion (IGM4982); f, mesial view of isolated tooth, with evidence of abrasive surface wear (IGM4984); g, 3D image and photography in lingual view (IGM4975); h, second tooth position, lingual expansion of tooth row to its base; $\mathbf{i}$, ninth tooth position, showing the apicollingual attachment; $\mathbf{j}$, twelfth tooth postion, more apically but with the contribution of its base to the tooth row. D, dentary, M, maxilla, pmx, premaxilla, rt, replacement tooth, ft, functional tooth. Scale bar in $\mathbf{a}, \mathbf{b}, \mathbf{d}, \mathbf{h}, \mathbf{i}$ and $\mathbf{j}$ equals $1 \mathrm{~mm}$; in $\mathbf{c}$, e and $\mathbf{g}$ equals $5 \mathrm{~mm}$, f equals $100 \mu \mathrm{m}$. 
a

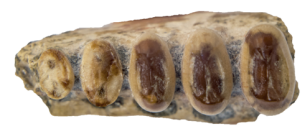

d

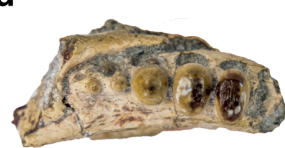

g

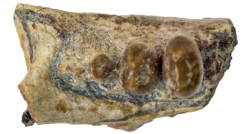

j

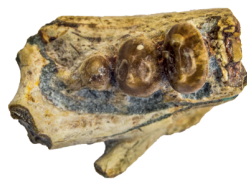

m

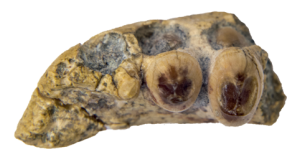

p

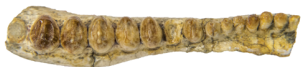

S

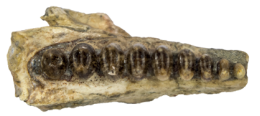

b

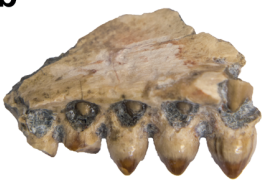

e

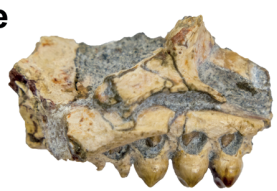

h

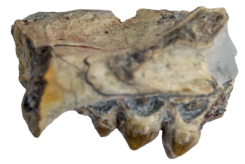

$\mathbf{k}$

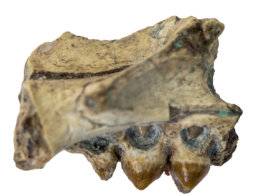

n

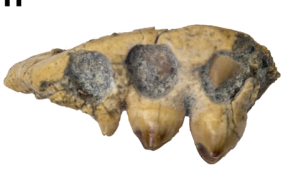

q

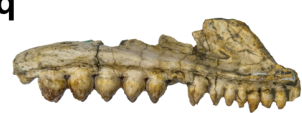

$\mathbf{t}$

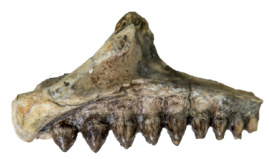

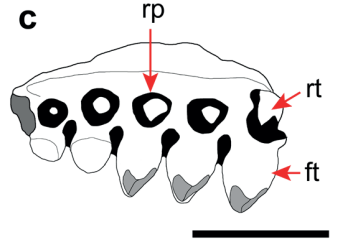

f

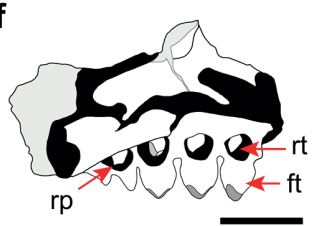

i

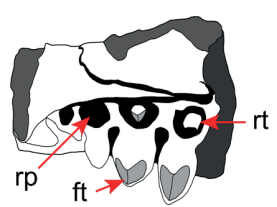

I

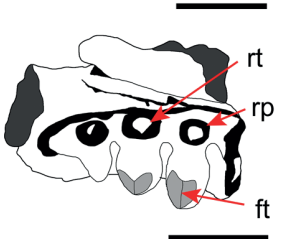

o

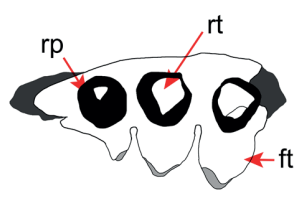

$\mathbf{r}$

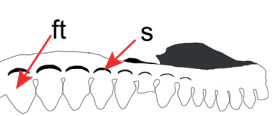

$\mathbf{u}$

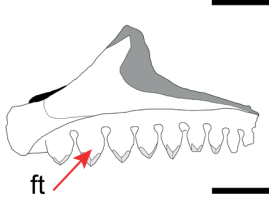

Figure 3 - Occlusal and labial view of upper jaws, a-c IGM4973, d-f IGM4974; g-i IGM4976; j-I IGM4977; m-o IGM4983; p-r IGM4980; s-u IGM4072. rp, resorption pit; s, scale. Scale bars equals $5 \mathrm{~mm}$.

that are connected by a U-shaped blade (Figure $2 \mathrm{f}$ ), conferring them a chisel-like appearance, as described by Nydam et al. (2007). The exception is the first bicuspid tooth ( $8^{\text {th }}$ tooth position), which has a lingual cusp slightly taller than the labial cusp. Additionally, there are accessory blades located mesially and distally that are weakly-developed and shallow (Figure 2f). In occlusal view, the maxillary tooth row of is sinusoidal. Ontogenetically older specimens (e.g., IGM4971) usually have the most posterior tooth of the series as tall as (or bigger than) the second last one, whereas juveniles (e.g., IGM4973) have one or two small posterior conical teeth being added posteriorly.

Dentary dentition: Dentary teeth are attached apicolingually to the lateral wall of the dentary, but 
some degree of variation occurs along the tooth row. CT scans from IGM4975 indicate that tooth bases are located lingually relative to the labial wall on the anterior portion of the tooth, whereas the posterior dentition is apicolingually placed on the labial wall of the dentary (Figure $2 \mathrm{~h}-\mathrm{j}$ ). As observed in the maxilla, the functional dentary teeth are fully ankylosed to the jaw bone, apart from the posteriormost tooth of juveniles (Table I). The dentary bears 15 tooth positions in the most complete specimen (Figure 4), with seven conical anterior teeth and eight molariform posterior teeth. Tooth morphology is the same as in the upper jaw, with teeth expanded labiolingually and bearing two conical cusps separated by a U-shaped blade. Additionally, the lingual cusp is slightly taller than the labial cusp anteriorly on the posterior tooth series, but both cusps become equal tall posteriorly on the tooth row. The maxillary and dentary teeth interdigitate (Figure 2c, e), in a similar manner to Polyglyphanodon sternbergi (Gilmore 1942, Nydam and Cifelli 2005, Simões et al. 2016).

\section{TOOTH REPLACEMENT}

Types of Replacement: We can identify specimens undergoing multiple stages of replacement (Figures 3 and 4). Active tooth replacement is observed on the maxillae and dentaries of specimens inferred as juveniles (Table I). In these specimens, the shape of the resorption pits is circular and they are positioned lingually to the functional tooth. Specimen IGM4980 has highly reduced and slitlike resorption (Figure 4g-i). These pits have slightly distinct degrees of development and occur only on the posterior tooth series. These slit-like pits are interpreted as being incipient (or early stage) resorption pits, which would precede the fully open and circular pit in the tooth life cycle (Figures 3p-r, 5), and thus characterize a stage before the replacement tooth could enter the pulp cavity. Complete absence of resorption pits occurs in specimens IGM4970a, IGM4970b, IGM4971, IGM4972 and IGM4982 (Figures 3 and 4), which are interpreted as lacking tooth replacement.

Although histological sections and CT scans were not possible to be conducted on specimens without resorption pits, the absence of replacement pits can be confidently used as an indication of absence of tooth replacement in some D. bajaensis specimens. That is because all reptiles that develop resorption pits during tooth replacement are known to maintain those pits open while the replacement dentition grows inside the pulp cavity of the functional tooth. This is true regardless of the location of the successional lamina, for instance, as this pattern is observed when the successional a

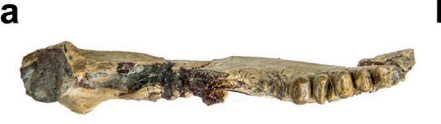

d

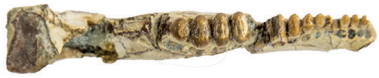

g

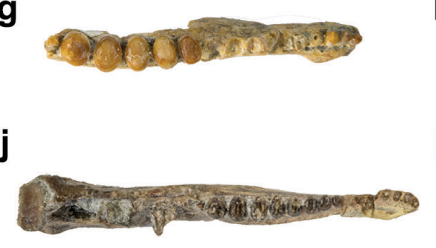

b

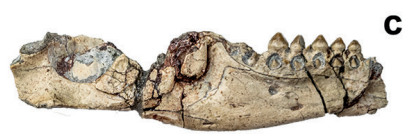

e

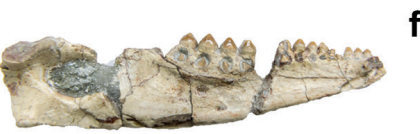

h

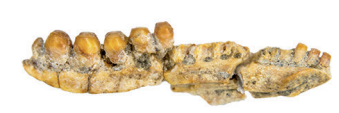

k

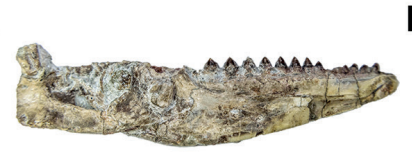

i

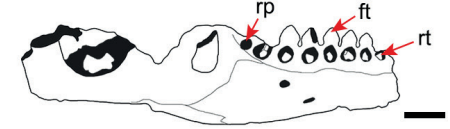

f
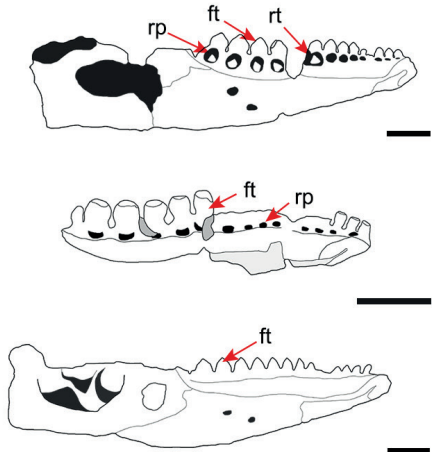

Figure 4 - Occlusal and lingual views of lower jaws; a-c IGM4978; d-f IGM4975; g-i IGM4981; j-I IGM4970a. Scale bars equals $5 \mathrm{~mm}$. 
TABLE I

Individual specimens and ontogenetic markers.

\begin{tabular}{|c|c|c|c|c|c|c|c|c|c|c|c|}
\hline Specimen & Locality & Element & $\begin{array}{c}\text { Dentary } \\
\text { length } \\
(\mathrm{cm})\end{array}$ & $\begin{array}{c}\text { Dentary } \\
\text { height } \\
(\mathrm{cm})\end{array}$ & $\begin{array}{c}\text { Maxilla } \\
\text { length } \\
(\mathrm{cm})\end{array}$ & $\begin{array}{l}\text { Tooth } \\
\text { wear }\end{array}$ & $\begin{array}{l}\text { Resorption } \\
\text { pits }\end{array}$ & $\begin{array}{c}\text { New teeth } \\
\text { being } \\
\text { added } \\
\text { posteriorly }\end{array}$ & $\begin{array}{c}\text { Last } \\
\text { tooth } \\
\text { fusion } \\
\text { to } \\
\text { dentary }\end{array}$ & $\begin{array}{c}\text { Inferred } \\
\text { Ontogenetic } \\
\text { stage }\end{array}$ & Stage \\
\hline IGM4978 & $0 \mathrm{Km}$ & Dentary & $?$ & 0.83 & - & Mild & Open & $?$ & $?$ & Juvenile?* & $\begin{array}{l}\mathrm{A} / \mathrm{B} \\
\text { (iii) }\end{array}$ \\
\hline IGM4975 & $0 \mathrm{Km}$ & Dentary & 2.32 & 0.85 & - & Mild & Open & $?$ & $?$ & Juvenile?* & $\begin{array}{l}\mathrm{A} / \mathrm{B} \\
\text { (iii) }\end{array}$ \\
\hline IGM4981 & Cadael & Dentary & 2.4 & $?$ & - & High & Open & Present & $?$ & Juvenile & B (iv) \\
\hline IGM4970a & Evelia & Dentary & 2.92 & 1 & - & Moderate & Absent & Absent & Present & Adult & $\mathrm{C}$ (iv) \\
\hline IGM4982 & Scorpio & $\begin{array}{l}\text { Maxilla } \\
\text { and } \\
\text { Dentary }\end{array}$ & $?$ & $?$ & $?$ & Mild & Absent & Absent & Present & Adult & $\begin{array}{c}\mathrm{C} \\
\text { (i-iii) }\end{array}$ \\
\hline IGM4973 & $0 \mathrm{Km}$ & Maxilla & - & - & $?$ & Mild & Open & Present & Absent & Juvenile & $\begin{array}{c}\text { A } \\
\text { (iii) }\end{array}$ \\
\hline IGM4974 & $0 \mathrm{Km}$ & Maxilla & - & - & $?$ & Mild & Open & Present & Absent & Juvenile & $\begin{array}{c}\text { A } \\
\text { (iii) }\end{array}$ \\
\hline IGM4976 & $0 \mathrm{Km}$ & Maxilla & - & - & $?$ & Mild & Open & Present & Absent & Juvenile & $\begin{array}{c}\text { A } \\
\text { (iii) }\end{array}$ \\
\hline IGM4977 & $0 \mathrm{Km}$ & Maxilla & - & - & $?$ & Mild & Open & Present & Absent & Juvenile & $\begin{array}{c}\text { A } \\
\text { (iii) }\end{array}$ \\
\hline IGM4979 & $0 \mathrm{Km}$ & Maxilla & - & - & $?$ & High & Open & $?$ & $?$ & $?$ & $\begin{array}{l}\mathrm{A} / \mathrm{B} \\
\text { (iv) }\end{array}$ \\
\hline IGM4983 & $0 \mathrm{Km}$ & Maxilla & - & - & $?$ & Mild & Open & Present & Absent & Juvenile & $\begin{array}{c}\mathrm{A} \\
\text { (iii) }\end{array}$ \\
\hline IGM4971 & Evelia & Maxilla & - & - & 1.62 & Mild & Absent & Absent & Present & Adult & C(i) \\
\hline IGM4970b & Evelia & Maxilla & - & - & 1.63 & Moderate & Absent & Absent & Present & Adult & C(iv) \\
\hline IGM4980 & Cadael & Maxilla & - & - & 1.71 & Moderate & Incipient & Present & Absent & Juvenile & B (ii) \\
\hline IGM4972 & Evelia & Premaxilla & - & - & - & Mild & Absent & - & - & $?$ & $?$ \\
\hline IGM4972 & Evelia & Maxilla & - & - & - & Moderate & Absent & $?$ & $?$ & $?$ & $\begin{array}{c}\mathrm{C} \\
\text { (iii) }\end{array}$ \\
\hline IGM4984 & Cadael & Tooth & - & - & - & Mild & $?$ & $?$ & $?$ & $?$ & $?$ \\
\hline
\end{tabular}

*Indicates specimens for which few discrete ontogenetic markers are visible, but size comparison with other jaw elements would suggest a juvenile (possibly sub-adult) stage. Ontogenetic effects are discounted as the specimens from locality $0 \mathrm{Km}$ come from the same layer. However, it should be noted that ontogenetic inferences based on size only can be affected by differential growth curves for different sexes.

"?" indicates missing data due to the incompleteness of the specimen.

“-“indicates not applicable.

lamina and replacement teeth develop inside a dental socket, as in crocodiles (Edmund 1960, Poole 1961) or outside of a socket, as in squamates (Edmund 1960, Osborn 1971). Therefore, in all reptiles that have replacement teeth migrating into the pulp cavity of the functional tooth (as it is the case with $D$. bajaensis), there cannot exist replacement teeth inside pulp cavities in the absence of resorption pits. The association of tooth replacement with observable resorption pits in the specific case of $D$. bajaensis is also corroborated by the CT scan cross sections of specimen IGM4975 (Figure $2 \mathrm{~h}-\mathrm{j}$ ), which has replacement teeth in different stages of development within the tooth row, and always occurring concomitantly with resorption pits. Additionally, the larger replacement tooth in D. bajaensis, and the larger resorption pit located lingually to it (see also Suppl. Mat.), 
indicating a direct correlation of replacement tooth and resorption pit size in this taxon.

Specimens of Dicothodon bajaensis with no active replacement also lack new teeth growing posteriorly, and the last tooth (when preserved) is fully ankylosed to the jaw bone. These latter two aspects of their morphology indicate those specimens had attained skeletal maturity (see Methods and Table I) when they stopped replacing their dentition. Additionally, those materials represent the largest specimens in our samples, including the largest dentary available (IGM4970b). All these factors indicate that specimens with arrested tooth replacement are the oldest individuals in our sample.

It is interesting to note that specimens of Dicothodon bajaensis with either incipient or fully developed resorption pits all have pits at fairly similar degrees of development throughout most of the tooth row (at least the entire posterior portion of the tooth row), with most of the pit size variation being due to the relative size of the functional tooth. This pattern is very similar to the condition observed in extant teiids, such as Tupinambis (Suppl. Mat.). This might be explained by the rates of tooth replacement. Whereas lizards with many replacement waves and fast replacement rates (e.g., pleurodont iguanian) depict numerous stages of the tooth cycle within the jaw (e.g., resorption pits, fully and partially ankylosed functional teeth, and shed tooth position), taxa with slower rates of replacement show more uniform patterns, with similar degrees of development of resorption pits and replacement teeth (e.g., Tupinambis and $D$. bajaensis). In the latter pattern, almost all posterior teeth have resorption pits at similar stages of replacement and all posterior functional teeth are ankylosed to the jaw. However, there are differences in size of the replacement teeth developing inside the resorption pits (see Tupinambis in Suppl. Mat. and relative tooth sizes of D. bajaensis in Table II).
One important additional aspect is that specimens IGM4970 and IGM4982 contain one dentary and one maxilla from the same individuals, and from the same side of the head (Figure 2c, e). The dentaries and maxillae of both IGM4970 and IGM4982 are in the same stage of tooth replacement and tooth wear. Therefore, tooth replacement in $D$. bajaensis was symmetrical, as proposed by Cooper

TABLE II

Relative tooth sizes.

\begin{tabular}{|c|c|c|c|c|}
\hline \multicolumn{5}{|c|}{ Upper Jaw } \\
\hline Specimen & $\begin{array}{c}\text { Tooth } \\
\text { position }\end{array}$ & $\begin{array}{l}\text { Functional } \\
\text { tooth }(\mathrm{mm})\end{array}$ & $\begin{array}{l}\text { Replacement } \\
\text { tooth }(\mathrm{mm})\end{array}$ & $\begin{array}{c}\text { Relative } \\
\text { size }\end{array}$ \\
\hline \multirow{5}{*}{ IGM4974 } & 11 & 2.09 & 1.05 & 0.41 \\
\hline & 12 & 2.04 & 0.97 & 0.40 \\
\hline & 13 & 2.38 & 1.26 & 0.47 \\
\hline & 14 & 1.4 & $?$ & $?$ \\
\hline & 15 & 0.67 & $?$ & $?$ \\
\hline \multirow{2}{*}{ IGM4983 } & 13 & 2.15 & 1.55 & 0.72 \\
\hline & 14 & 2.08 & 1.45 & 0.70 \\
\hline \multirow{15}{*}{ IGM4975 } & 1 & Broken & Empty & $?$ \\
\hline & 2 & 1.29 & 0.46 & 0.36 \\
\hline & 3 & 1.46 & $?$ & $?^{*}$ \\
\hline & 4 & 1.65 & 0.76 & 0.46 \\
\hline & 5 & Broken & Empty & $?$ \\
\hline & 6 & Broken & Empty & $?$ \\
\hline & 7 & 1.58 & 0.53 & 0.34 \\
\hline & 8 & 1.59 & 0.65 & 0.41 \\
\hline & 9 & 1.68 & 0.68 & 0.40 \\
\hline & 10 & 1.64 & 0.77 & 0.47 \\
\hline & 11 & Broken & Broken & $?$ \\
\hline & 12 & 2.22 & 0.84 & 0.40 \\
\hline & 13 & 2.23 & 1.01 & 0.45 \\
\hline & 14 & 2.28 & 1.03 & 0.45 \\
\hline & 15 & 1.99 & 1.09 & 0.55 \\
\hline \multirow{5}{*}{ IGM4978 } & 10 & 1.9 & $?$ & $?$ \\
\hline & 11 & 2.01 & $?$ & $?$ \\
\hline & 12 & 2.09 & 1.14 & 0.55 \\
\hline & 13 & 1.78 & 1.04 & 0.58 \\
\hline & 14 & 2.32 & 1.21 & 0.52 \\
\hline
\end{tabular}

Symbols used: "?" indicates missing data due to the incompleteness of the specimen; * Some doubts remain regarding the absence or presence of a replacement tooth at this position (see text for details). 
et al. (1970) for the tooth replacement models within Squamata.

Patterns of tooth wear: In most specimens that exhibit active replacement and features indicative of younger ontogenetic stages tooth wear is usually mild. In specimens without active replacement (and features linked to older ontogenetic stages) tooth wear is usually greater (Table I). This is expected since older individuals in which replacement had ceased would not have been able to replace extremely worn dentition. However, a few specimens with active replacement display some significant wearing of the enamel, such as specimens IGM4979 and IGM4981. These specimens are inferred to have teeth at an advanced stage of the tooth life cycle, which would accumulate a detectable amount of wear just before being shed and replaced (Figure 5). Therefore, while intensive tooth wear could occur at all ontogenetic stages, it occurred more frequently in adult individuals that ceased tooth replacement.

Replacement waves: Specimen IGM4975 is almost completely preserved, still has active replacement, and allows some estimation on the number of replacement waves - see Table II and Figure 2g. Relative tooth sizes (see Material and Methods) are a good indicator of the increasing size of the replacement dentition relative to fully functional teeth, thus being indicative of size variation within each replacement wave. From the seventh tooth until the last tooth position, increasing relative size of the replacement teeth between tooth positions 7 and 10, and then, from 12 to 15 , indicate those two teeth groups represent different replacement waves. Anteriorly, fewer replacement teeth are preserved to allow relative tooth size estimates. However, considering the size of the replacement waves detected posteriorly (4-5 teeth), tooth positions 1 to 4 would likely form a single, more anteriorly located, replacement wave. This anteriormost replacement wave would be

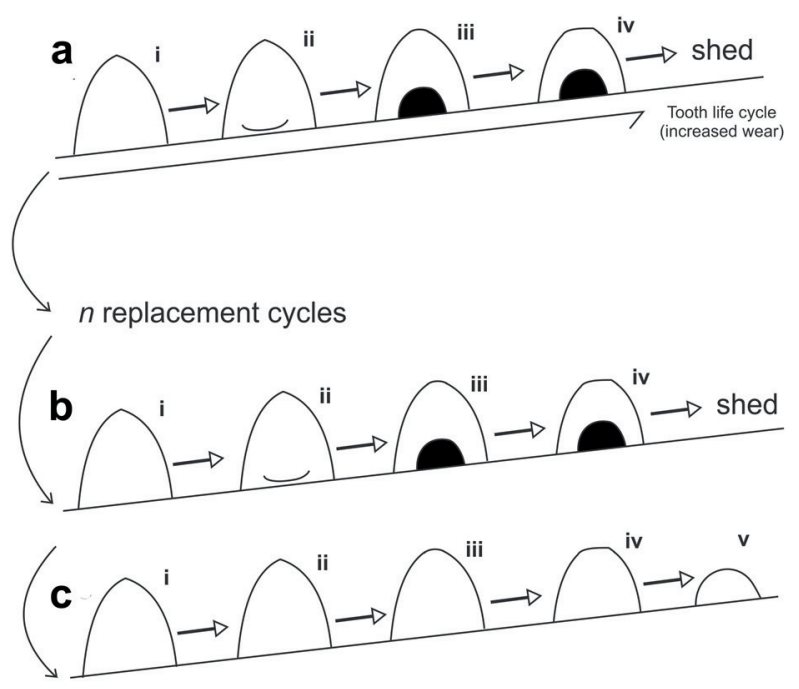

Figure 5 - Schematic drawing of the replacement cycles and the changes in tooth wear and appearance of the resorption pit within each tooth generation (exemplified by a single tooth from each generation). a, juvenile tooth generation; $\mathbf{b}$, penultimate tooth generation; $\mathbf{c}$, last tooth generation.

separated from the wave in positions $7-10$ by the empty resorption pits in positions five and six.

Feeding implications: The dental morphology, including interdigitate teeth, tooth wear patterns and cessation of tooth replacement, provide the opportunity to analyze the paleodiet of $D$. bajaensis. The apparently slow replacement in the early ontogenetic stages of D. bajaensis (only a few waves and high degree of wear before replacing them, as shown in IGM4979 and IGM4981), followed by the complete cessation of replacement later in life, contributed to a precise tooth interdigitation (Figure 2e) and thus, more efficient food processing.

The presence of cusps and blades on the posterior dentition could represent an adaptation for complex food processing, in which the blades could work as shearing surfaces while the cusps only maintain the food in place (Brizuela and Albino 2009). Additionally, the well-developed crest connecting the two cusps and the accessory mesial and distal ridges (as also observed in Po. sternbergi) would make the dentition in D. bajaensis 
well adapted to crop leaves, which is quite different from the well-developed cusps and absence of cutting blades in taxa that are mostly insectivorous, like Teius teyou (Milstead 1961). Also, the heavy wear present on the cusps across all occlusal surfaces (IGM4979 and IGM4981 - Figures 2a, $4 \mathrm{~g}-\mathrm{i}$ ) indicate that oral food processing (chewing) or crushing, may have been important for this taxon, thus, differing from the pattern inferred for Po. sternbergi (Simões et al. 2016). For instance, fossil snails and mollusks have been previously reported in this formation (García-Alcantara 2016), and could have been a dietary component of D. bajaensis. Finally, despite the difference in the adult dentition between D. bajaensis and insectivorous taxa like Teius, it is likely that insects could have been an important dietary component during early ontogeny in D. bajaensis as a source of protein, as observed in numerous extant lizards (Montanucci 1968, Pough 1973, Presch 1974, Estes and Williams 1984). Therefore, considering the complex tooth morphology in D. bajaensis, it is suggested that its dentition was well-adapted to eat a large variety of food sources, such as in some extant teiid lizards with heterodont dentition and complex dental morphologies (e.g., Tupinambis), that feed on insects, vertebrates, vegetables, and snails (Dessem 1985).

\section{DISCUSSION}

The replacement pattern observed in Dicothodon bajaensis implies a late cessation of tooth replacement during the ontogeny: specimens with juvenile features displaying active replacement and older individuals lacking active replacement and displaying more tooth wear (Figure 5). It is important to note, however, that the specimens come from different localities corresponding to different depositional events (D. Fastovsky, prs. com. to MLC 2017) and so, they did not belong to the same death assemblage, nor the same local population. Nevertheless, discrete ontogenetic markers (such as posterior addition of teeth to the tooth row) are relatively constant within a species, and across different taxa in acrodontan lizards (Cooper et al. 1970, Cooper and Poole 1973; see also Methods). Also, although most juveniles come from a single locality $(0 \mathrm{Km})$, juveniles and adults were found across distinct localities. Therefore, the general pattern inferred herein would not be affected by sampling individuals from distinct populations, although the exact timing of some ontogenetic events remains unclear. For instance, some of the specimens still displaying replacement are relatively large specimens compared to fully mature ones, indicating cessation of replacement would have occurred in relatively old juveniles, and clearly long after embryonic or hatchling stage. However, it remains unknown if replacement would have stopped close to, or into adulthood (skeletal maturity).

The general pattern in the timing of arrested tooth replacement in D. bajaensis departs from most other borioteiioids and other squamates. For instance, a number of taxa are known to have active tooth replacement throughout ontogeny, such as Bicuspidon (Nydam and Cifelli 2002, Folie and Codrea 2005), Cherminisaurus kozlowskii (Sulimski 1975), and Gilmoreteius (Sulimski 1975, Gao and Norell 2000. In other cases, complete absence of replacement has been reported for some borioteiioids, such as Polyglyphanodon sternbergi, which lacks resorption pits in juveniles and adults, and probably added teeth to the back of the tooth row, as performed by acrodontan lizards (Gilmore 1942, Nydam 1999, Nydam and Cifelli 2005, Nydam et al. 2007, Simões et al. 2016). Absence of replacement has also been detected in Gobinatus arenosus, from the Late Cretaceous of Mongolia (Gao and Norell 2000). However, cessation of tooth replacement in the entire tooth row during late post-embryonic ontogeny has never been confirmed in borioteiioids, or any other squamates. 
The borioteiioid Pe. aquilonius (Nydam et al. 2000), also from the Late Cretaceous of North America, presents resorption pits in odd tooth positions until the seventh tooth, but no evidence of tooth replacement was detected in the posterior tooth series. Also, its posterior tooth series has strong wearing, which suggests that teeth were used for a long time without replacement. These observations were used to suggest that Pe. aquilonius ceased the posterior tooth replacement as an adaptation for more efficient oral food processing, similarly to tribosphenic mammals (Nydam et al. 2000). However, the limited number of well - preserved specimens available for Pe. aquilonius hampers a precise establishment of how its replacement mode changed throughout ontogeny. The new materials described herein of $D$. bajaensis are, therefore, the first squamate for which cessation of tooth replacement in late ontogeny could be detected, considering individuals of different size classes and discrete ontogenetic markers. Given the close phylogenetic relationships between Dicothodon and Peneteius (Nydam et al. 2007), it would not be unlikely that this pattern first predicted and proposed by Nydam et al. (2000) indeed would have occured in Pe. aquilonius.

Besides D. bajaensis and possibly P. aquilonius, a late cessation in tooth replacement may also have occurred in Adamisaurus magnidentatus, from the Late Cretaceous of Mongolia. The tooth replacement pattern of $A$. magnidentatus has been described as an aberrant iguanid mode of tooth replacement (Sulimski 1978). Active tooth replacement, detected by replacement teeth within resorption pits, was indeed observed by us (specimens MgR-III/1, MgR-III/3, and MgRIII/ - pictures from Dr. Halamski), and also as reported by Gao and Norell (2000) and Sulimski (1972, 1978). However, one specimen lacks any form of resorption pits or any other externally visible evidence of tooth replacement (specimen MgR-II/50, pictures of Dr. Halamski). This latter pattern is, as far as we know, unreported in the literature and is similar to the cessation of tooth replacement during late ontogeny that is also seen in $D$. bajaensis. This would suggest that cessation of tooth replacement during adulthood could have occurred among Asian borioteiioids. However, a careful analysis of the available specimens of Adamisaurus is needed in order to better assess whether these changes in tooth replacement are actually changes in ontogeny, and are not related to taxonomy or taphonomic/preservational biases.

Borioteiioids show a plethora of distinct replacement modes and tooth implantation types. The evolution of those different patterns remains, however, mostly obscured. The mode of tooth replacement detected in D. bajaensis, thus, sheds some light into the evolution of different types of replacement within borioteiioids. The timing of arrested tooth replacement during ontogeny in $D$. bajaensis is intermediary between the continuous replacement mode (as in Bicuspidon) and the early ontogenetic cessation of tooth replacement (as inferred for Polyglyphanodon) among North American borioteiioids. Therefore, this difference in ontogenetic timing for the cessation of tooth replacement indicates a heterochronic pattern in the evolution of borioteiioids. If the genetic control of this mechanism in borioteiioids was similar to that of extant lizards - e.g., negligible levels of expression of Axin2 and Tcf7 have been linked to a vestigial successional lamina in Pogona (Richman and Handigran 2011) - then, the heterochronic effects could be the result of variable degrees of expression of Axin 2 and Tcf7 (or other genes associated to the dental lamina in borioteiioids) throughout post-embryonic development.

The mode of replacement detected herein for $D$. bajaensis is especially unusual when all other squamates and lepidosaurian reptiles are considered. Most lizards and snakes replace their teeth continuously during their whole life. Taxa displaying cessation of tooth replacement, such as 
acrodontan lizards and rhynchocephalians, cease replacement of their posterior tooth series very early during their ontogeny, with post-embryonic replacement restricted to very young individuals, or no replacement occurring at all (Edmund 1969, 1960, Cooper et al. 1970, Cooper and Poole 1973). Therefore, the pattern identified herein for D. bajaensis, and potentially also occurring in some other borioteiioids (e.g., Peneteius and Adamisaurus), is not only new to borioteiioids, but also represents a very unusual timing for cessation of tooth replacement across all lepidosaurs.

\section{CONCLUSIONS}

Dicothodon bajaensis was initially described based only on isolated teeth and fragments of jaws (Nydam 1999, Nydam et al. 2007), but the new materials of D. bajaensis described herein clarify important aspects on jaw and dental morphology, feeding implications, and ontogenetic changes in tooth replacement mode. Therefore, our finding expands on the variety of tooth implantation types and replacement modes in borioteiioids, and squamates in general. Tooth morphology and wear indicate $D$. bajaensis probably had a diverse diet that included elements that created intensive tooth wear (e.g., snails). Furthermore, the posterior teeth were placed apicolingually on the jaw bone, similarly to extant agamid lizards. The quite different timing on the rates of tooth replacement in D. bajaensis, Penenteius and Polyglyphanodon indicates a strong heterochrony in the patterns of arrested tooth replacement among these taxa that have been previously proposed as closely related (Nydam et al. 2007). Finally, the ontogenetic changes in tooth replacement pattern in $D$. bajaensis (possibly also present in Peneteius and Adamisaurus) is rare among lepidosaurs, as most lepidosaurs either replace their teeth continuously during their life, or cease tooth replacement very early during ontogeny, such as in most acrodontans and rhyncocephalians.

\section{ACKNOWLEDGMENTS}

We are grateful to the families Acevedo and Rojas for all their help during the field seasons and granted us to use their properties. We extend our thanks to all the participants of all the field seasons to Baja California since 2004 to 2015, especially René Hernández, Gerardo Álvarez, Gregory Wilson, and Oliver López for discovering, the amazing microsite $0 \mathrm{Km}$. Also, we are thankful with Laboratorio Nacional de Manufactura Aditiva, Digitalización 3D y Tomografía Computarizada (MADit) for the service provided in the digitalization of specimen IGM4975 (Dr. Leopoldo Ruiz Huerta and Dr. Alberto Caballero Ruiz), Dr. Marino Aquino and Dra. María del Carmen Silvestre from Facultad de Odontología, UNAM, for their help with all the radiological images, and Juan Miguel Contreras for photographing the specimens. We thank Dr. A. LeBlanc for discussions, Dr. R. L. Nydam for providing pictures of Bicuspidon, Dr. A. Halamaski who provided pictures of Adamisaurus magnidentatus, and the Smithsonian National Museum of Natural History for allowing MLCA to photograph the specimens of Polyglyphanodon sternbergi. MCLA is thankful to the Posgrado en Ciencias Biológicas, UNAM and Consejo Nacional de Ciencia y Tecnología (CONACyT) for the scholarship and support during the graduate studies. TRS thanks the Izaak Walton Killam Memorial Scholarship program for a $\mathrm{PhD}$ scholarship. Financial support of Dirección General de Asuntos del Personal Académico PAPITT IN 111209-2, IN104506-2, IN 100913 IN 103616, UC Mexus 2004-2005, University of Washington, and American Philosophical Society is deeply appreciated and recognized. We also thank four reviewers for their comments and suggestions that helped improve the manuscript. 


\section{REFERENCES}

APESTEGUÍA S, DAZA JD, SIMÕES TR AND RAGE JC. 2016. The first iguanian lizard from the Mesozoic of Africa. R Soc Open Sci 3: 160462.

BERKOVITZ B. 2000. Tooth replacement patterns nonmammalian vertebrates. In: Mark F, Smith M and Ferguson M (Eds), Development, Function and Evolution of Teeth. Cambridge University Press: Cambridge, p. 186-200.

BORSUK-BIALYNCKA M. 1996. The Late Cretaceous lizard Pleurodontagama and the origin of tooth permanency in Lepidosauria. Acta Paleontol Pol 42: 231-252.

BRIZUELA S AND ALBINO A. 2009. The dentition of the Neotropical lizard genus Teius Merrem 1820 (Squamata Teiidae). Trop Zool 22: 183-193.

BUDNEY LA, CALDWELL MW AND ALBINO AM. 2006. Tooth socket histology in the Cretaceous snake Dinilysia, with a review of amniote dental attachment tissues. J Vert Paleontol 26: 138-145.

BUTCHTOVÁ M, ZAHRADNÍČEK O, BALKOVÁ S AND TUCKER A. 2013. Odontogenesis in the Veiled Chameleon (Chamaeleo calyptratus). Arch Oral Biol 58: 118-113.

CALDWELL MW. 2007. Ontogeny, anatomy and attachment of the dentition in mosasaurs (Mosasauridae: Squamata). Zool J Linn Soc 149: 687-700.

CALDWELL MW, BUDNEY LA AND LAMOUREUX DO. 2003. Histology of tooth attachment tissues in the Late Cretaceous mosasaurid Platecarpus. J Vert Paleontol 23: 622-630.

CHAVARRÍA-ARELLANO M. 2014. Tipo de locomoción y hábito alimenticio del Teiido Dicothodon bajaensis del Cretácico Tardío, Baja California, México. Bachelor Thesis. Universidad Nacional Autónoma de México, 58 p.

COOPER JS. 1966. Tooth replacement in the slow worm (Anguis fragilis). J Zool 150: 235-248.

COOPER JS AND POOLE DFG. 1973. The dentition and dental tissues of agamid lizard, Uromastyx. J Zool 169: 85-100.

COOPER JS, POOLE DFG AND LAWSON R. 1970. The dentition of agamid lizards with special reference to tooth replacement. J Zool 162: 85-98.

DELGADO S, DAVIT-BEAL T AND JEAN-YVES S. 2003. Dentition and tooth replacement pattern in Chalcides (Squamata; Scincidae). J Morphol 256: 146-159.

DESSEM D. 1985. Ontogenetic changes in the dentition and diet of Tupinambis (Lacertilia: Teiidae). Copeia 1: 245247.

DURTSCHE RD. 2000. Ontogenetic plasticity of food habits in the Mexican spiny-tailed iguana, Ctenosaura pectinata. Oecologia 124: 185-195.
EDMUND G. 1960. Tooth Remplacement Phenomena in the Lower Vertebrates. University of Toronto Press, Toronto, $204 \mathrm{p}$.

EDMUND G. 1969. Dentition. In: Gans C (Ed), Biology of the Reptilia. Academic Press, New York, p. 117-200.

ESTES R AND WILLIAMS E. 1984. Ontogenetic variation in the molariform teeth of lizards. J Vertebr Paleontol 4: 96-107.

FOLIE A AND CODREA VA. 2005. New lissamphibians and squamates from the Maastrichtian of Hateg Basin, Romania. Acta Paleontol Pol 50: 57-71.

GAO K AND NORELL MA. 2000. Taxonomic composition and systematics of Late Cretaceous lizard assemblages from Ukhaa Tolgod and adjacent localities, Mongolian Gobi Desert. Bull Am Museum Nat Hist 249: 1-118.

GARCÍA-ALCANTARA D. 2016. Microvertebrados cretácicos de la localidad Fiesta de Huesos, El Rosario, Baja California, México. Bachelor Thesis. Universidad Nacional Autónoma de México, 158 p.

GAUTHIER JA, KEARNEY M, MAISANO JA, RIEPPEL O AND BEHLKE ADB. 2012. Asembling the Squamate Tree of Life : Perspectives from the Phenotype and the Fossil Record. B Peabody Mus Nat Hi 53: 3-308.

GILMORE CW. 1942. Osteology of Polyglyphanodon, an Upper Cretaceous Lizard from Utah. Smithson Misc Collect: 229-265.

LUAN X, WALKER C, DANGARIA S, ITO Y, DRUZINSKY R, JAROSIUS K, LESOT H AND RIPPEL O. 2009. The mosasaur tooth attachment apparats as paradigm for the evolution of the gnathostome periodontium. Evol Dev 11: 247-259.

MILSTEAD WW. 1961. Notes on Teiid lizards on Southern Brazil. Copeia 1961: 493-495.

MONTANUCCI RR. 1968. Comparative dentition in four Iguanid lizards. Herpetologica 24: 305-315.

MONTELLANO-BALLESTEROS M, WILSON G, ÁLVAREZ-REYES G, HERNÁNDEZ-RIVERA R, QUINTERO E AND ARANDA-MANTECA F. 2005. New material of Polyglyphanodon bajaensis from El Rosario Baja California, Mexico. J Vertebr Paleontol 25: 93A.

MONTELLANO-BALLESTEROS M, WILSON G, HERNÁNDEZ-RIVERA R, ÁLVAREZ-REYES G AND ARANDA-MANTECA F. 2008. Microvertebrados de la Formación El Gallo (Cretácico Superior), Baja California, México. In: III Congreso Latinoamericano de Paleontología de Vertebrados, $161 \mathrm{p}$.

NESSOV LA. 1988. Late Mesozoic amphibians and lizards of Soviet Middle Asia. Acta Zool Cracoviensia 31: 475-486.

NYDAM RL. 1999. Polyglyphanodontinae (Squamata: Teiidae) from the medial and Late Cretaceous: new taxa from Utah, U.S.A. and Baja California del Norte, Mexico. 
In: Gillete D (Ed), Vertebrate Paleontology in Utah. Miscellaneous Publication, p. 303-317.

NYDAM RL. 2013. Squamates from the Jurassic and Cretaceous of North America. Palaeobiodivers Palaeoenviron 93: 535-565.

NYDAM RL AND CIFELLI RL. 2002. A new lizard from the Cedar Moountain Formation (Albian-Cenomanian Boundary) of Utah. J Vertebr Paleontol 22: 276-285.

NYDAM RL AND CIFELLI RL. 2005. New data in the dentition of the scincomorphan lizard Polyglyphanodon sternbergi. Acta Paleontol Pol 50: 73-78.

NYDAM RL, EATON JG AND SANKEY J. 2007. New taxa of transversely-toothed lizards (Squamata: Scincomorpha) and new information on the evolutionary history of “Teiids." J Paleontol 81: 538-549.

NYDAM RL, GAUTHIER JA AND CHIMENT J. 2000. The mammal-like teeth of the Late Cretaceous lizard Peneteius aquilonius Estes 1969 (Squamata,Teiidae). J Vertebr Paleontol 20: 628-631.

NYDAM RL, ROWE TB AND CIFELLI RL. 2013. Lizards and snakes of the Terlingua Local Fauna (late Campanian), Aguja Formation, Texas, with comments on the distribution of paracontemporaneous squamates throughout the Western Interior of North America. J Vertebr Paleontol 33: 1081-1099.

POOLE F. 1961 Notes on tooth replacement in the nile crocodile Crocodilus niloticus. J Zool 136: 131-140.

POUGH F. 1973. Lizard energetics and diet. Ecology 54: 837844.

PRESCH W. 1974. A survey of dentition of the Macroteiid lizards (Teiidae: Lacertilia). Herpetologica 30: 344-349.

RICHMAN JM AND HANDRIGAN GR. 2011. Reptilian tooth development. genesis 49: 247-260.
ROMO DE VIVAR P. 2011. Microvertebrados cretácicos tardíos del área de El Rosario, Baja California, México. Bachelor Thesis. Universidad Nacional Autónoma de México, 158 p.

SIMÕES TR, CALDWELL MW, PALCI A AND NYDAM RL. 2017. Giant taxon-character matrices: quality of character constructions remains critical regardless of size. Cladistics 33: 198-219.

SIMÕES TR, FUNSTON GF, VAFAEIAN B, NYDAM RL, DOSCHAK MR AND CALDWELL MW. 2016. Reacquisition of the lower temporal ar in sexually dimorphic fossil lizards provides a rare case of convergent evolution. Sci Reports 6: 1-12.

SIMÕES TR, WILNER E, CALDWELL MW, WEINSCHÜTZ LC AND KELLNER AWA. 2015. A stem acrodotan lizard in the Cretaceous of Brazil revises early lizard evolution in Gondwana. Commun 6(8149): $1-7$.

SULIMSKI A. 1972. Admisaurus magnidentatus n. gen., n. sp. (Sauria) from the Upper Cretaceous of Mongolia. Acta Paleontol Pol 27: 33-40.

SULIMSKI A. 1975. Macrocephalosauridae and Polyglyphanodontidae (Sauria) from the Cretaceous of Mongolia. Acta Paleontol Pol 33: 25-102.

SULIMSKI A. 1978. New data on the genus Adamisauris Sulimski 1972 (Sauria) from the Upper Cretaceous of Mongolia. Paleontol Pol 38: 43-56.

\section{SUPPLEMENTARY MATERIAL}

Figures S1-S5. 